\title{
Malign mide çıkış obstrüksiyonunda endoskopik yöntemle metal stent uygulaması: Tersiyer bir merkezde beş ylllık tecrübe
}

Endoscopic metal stent placement for malignant gastric outlet obstruction: A 5-year experience at a tertiary care center

Nuretdin SUNA ${ }^{1}$, Ufuk Barış KUZU², Bülent ÖDEMIŞ², Selçuk DişiBEYAZ³ , Erkin ÖZTAŞ , Diğdem ÖZER ETIK ${ }^{1}$, Hakan YILDIZ ${ }^{4}$, Erkan PARLAK ${ }^{5}$

${ }^{1}$ Başkent Üniversitesi Tip Fakültesi, Gastroenteroloji Bilim Dall, Ankara

${ }^{2}$ Türkiye Yüksek Ihtisas Eğitim ve Araştırma Hastanesi, Gastroenteroloji Kliniği, Ankara

${ }^{3}$ Eskişshir Osmangazi Üniversitesi Tip Fakültesi, Gastroenteroloji Bilim Dal, Eskişehir

${ }^{4}$ Biruni Üniversitesi Tip Fakültesi, Gastroenteroloji Bilim Dah, Istanbul

${ }^{5}$ Hacettepe Universitesi Tip Fakültesi, Gastroenteroloji Bilim Dal, Ankara

Giriş ve Amaç: Malign mide çıkış obstrüksiyonu, özellikle pankreas ve mide kanserlerinde olmak üzere intraabdominal malignitelerin geç ve yaygın bir komplikasyonudur. Bu hastaların çoğu küratif cerrahi tedaviye uygun olmadıkları için palyatif tedavi yöntemlerine gereksinim duymaktadırlar. Palyatif amaçlı yapılan cerrahi yöntemlere göre daha az invaziv bir yöntem olan endoskopik yolla duodenal kendiliğinden genişleyebilen metal stent yerleştirme son yıllarda daha çok kullanılmaktadır. Bu retrospektif tek merkezli çalışmanın amacı, inoperabl malign mide çıkış obstrüksiyonu olan hastalarda endoskopik olarak uygulanan duodenal kendiliğinden genişleyebilen metal stent yönteminin güvenilirliğini ve etkinliğini saptamaktır. Gereç ve Yöntem: Endoskopi ünitemizde beş yıllık dönemde malign mide çıkış obstrüksiyonu nedeniyle duodenal kapsız kendiliğinden genişleyebilen metal stent uygulanan hastalarm verileri retrospektif olarak incelendi. Dudenal kendiliğinden genişleyebilen metal stent yerleştirmenin teknik ve klinik başarıs ile komplikasyonları değerlendirildi. Bulgular: Malign mide çıkıs obstrüksiyonu olan toplam 28 hastaya palyatif amaçl endoskopik yol ile duodenal kapsız kendiliğinden genişleyebilen metal stent yerleștirildi. Hastaların tamamında teknik başarı elde edildi. Klinik başarı ise 25 (\%89.3) hastada sağlandı. Hastaların ortalama Gastrik Outlet Obstrüksiyon Skorlama Sistemi skorunun, duodenal stent yerleştirmeden önce 0.536 iken duodenal stent yerleștirildikten iki hafta sonra 2.39'a yükseldiği görüldü ( $P=0.0001)$. Majör komplikasyon 2 (7.14) ve minör komplikasyon 2 (\%7.14) hastada gelişti. Sonuç: Saptanan bulgular ışığında küratif cerrahi tedaviye uygun olmayan malign mide çıkış obstrüksiyonlu hastalarda endoskopik olarak uygulanan kendiliğinden genişleyebilen metal stent güvenli ve etkili bir palyatif yöntemdir.

Anahtar kelimeler: Mide çıkış obstrüksiyonu, malign tümör, metal stent

\section{GİRIS}

Malign mide çıkış obstrüksiyonu (MMÇO), özellikle pankreas ve mide kanserleri olmak üzere intraabdominal malignitelerin geç ve yaygin bir komplikasyonudur. Mide veya pankreas kanseri gibi çeşitli gastrointestinal maligniteleri olan hastaların yaklaşık \%15-20'sinde MMÇO gelişir. Örneğin, distal mide kanseri olan hastalarda \%35 ve pankreas kanseri olan hastalarda \%20 oranında görülür (1-4). Inatçı bulantı-kusma,
Background and Aims: Malignant gastric outlet obstruction is a late and common complication of intra-abdominal malignancies, particularly primary pancreatic or gastric carcinomas. The majority of patients considered as unsuitable for curative surgical treatment require palliative treatment methods. Recently, endoscopic self-expendable metal stent placement, which is a minimally invasive method compared with surgery, has been performed more frequently than palliative surgery. The aim of this retrospective study was to evaluate the safety and efficacy of self-expendable metal stent placement in patients with inoperable malignant gastric outlet obstruction. Materials and Methods: This study analyzed the data of patients who underwent endoscopic uncovered self-expendable metal stents placement in the duodenum for treating malignant gastric outlet obstruction during a period of 5 years in our endoscopy unit. Technical and clinical success of the placement of duodenal self-expendable metal stents and the complications of the procedure were evaluated. Results: A total of 28 patients with malignant gastric outlet obstruction underwent endoscopic self-expendable metal stent placement. Technical success was achieved in all patients, while clinical success was observed in 25 patients (89\%). According to the gastric outlet obstruction scoring system, the mean score of the patients was 0.536 before stent placement and improved significantly to 2.39 at the second week after stent placement $(p=0.0001)$. Major complications were observed in two patients (7.14\%), and minor complications were observed in another two patients (7.14\%). Conclusion: These findings indicate that endoscopic self-expendable metal stent placement was a safe and efficient palliative procedure for patients considered as unsuitable for curative surgical treatment of malignant gastric outlet obstruction.

Key words: Keywords: gastric outlet obstruction, malignant tumor, metal stent

dehidratasyon, malnütrisyon, kaşeksi ve kötü yaşam kalitesi gibi önemli semptom ve bulgulara neden olur (5). Prognozları kötü olup ortalama sağ kalım sadece 3-4 aydır (6).

MMÇO olan hastaların büyük çoğunluğu küratif cerrahi tedaviye uygun olmadıkları için palyatif tedavi yöntemlerine gereksinim duymaktadırlar. Bu hastalar için palyatif tedavinin birincil amacı obstrüksiyona bağlı gelişen semptomların 
hafifletilmesidir. Geleneksel olarak, MMÇO'nun palyatif tedavisinde cerrahi yöntem olan gastrojejunostomi (GJ) yapılmaktadır. Ancak bu prosedürün ciddi morbidite ve mortalite ile ilişkili olduğu bilinmektedir (7). Palyatif amaçlı yapılan cerrahi yöntemlere göre daha az invaziv bir yöntem olan endoskopik yolla duodenal kendiliğinden genişleyebilen metal stent (KGMS) yerleștirilmesi son yllarda kullanılmaktadır. Bildirilen teknik başarı oranları \%94-100 ve klinik başarı oranları \%77-94 arasında değişmektedir (8-20). Ayrıca cerrahi tedavi yöntemi ile karşılaştırıldığında, endoskopik yolla KGMS uygulanmasi, daha iyi tolere edilmekte ve hastanede kalış süresi kısalmaktadır $(6,21,22)$.

Retrospektif tek merkezli bu çalışmanın amacı, inoperabl MMÇO olan hastalarda endoskopik olarak uygulanan duodenal kapsız KGMS yönteminin güvenilirliğini ve etkinliğini saptamaktır.

\section{GEREC ve YÖNTEM}

Endoskopi ünitemizde 01 Ocak 2010-31 Aralık 2015 tarihleri arasında inoperabl MMÇO nedeniyle endoskopik yolla duodenal kapsız KGMS yerleştirilen 28 hastanın verileri retrospektif olarak incelendi. "Gastrik Outlet Obstrüksiyon Skorlama Sistemi (GOOSS)" skoru (0=Oral alım yok, $1=$ Sivl diyet, $2=$ =Yumuşak katı diyet, 3=Düşük kalıntı veya normal diyet) $\leq 2$ olan hastalara KGMS uygulandı (3). Dışlama kriterleri; $1 . \leq 18$ yass, 2. Mide proksimalinde, distal ince barsakta veya kolonda obstrüksiyon, 3. Daha önce aynı yere metal stent yerleştirilmiş olması, 4. Endoskopik tedavi için kontrendikasyonların varlığı ve 5. Isslem sonrası takiplerini başka merkezde devam etme.

Dudenal kapsız KGMS uygulamasından birkaç gün önce, darlığın yerini, derecesini ve uzunluğunu değerlendirmek için bilgisayarlı tomografi ve üst gastrointestinal endoskopi yapıldı. Aspirasyon riskini en aza indirgemek ve gastrik boşalmayı sağlamak için işlemden 3 gün önce tüm hastalara sadece sıvı beslenme rejimi verildi. Işlemden bir gün önce abdominal ultrasonografi ile mide lümeni kontrol edildi ve lümeni dolu olan hastalara nazogastrik sonda takıldı.

Hastalara işlem öncesi \% 10'luk lidokain sprey ile boğaz anestezisi uygulandı. Işslem esnasında midazolam, meperidin ve propofol ile bilinçli sedasyon uygulandı. İşlemler Olympus duodenoskop (Olympus TJF 240, Japan, 4.2 mm çalışma kanallı) ile gerçekleştirildi. Duodenoskopun ucu darlığın önündeki bölgeye yerleştirildi. Daha sonra duodenoskopun çalışma kanalı boyunca ilerletilen klavuz tel (Jagwire 0.035 inç, Boston Scientific, USA) yüklü endoskopik retrograt kolanjiyopankreatografi (ERKP) kateteri (Boston Scientific, USA) ile darlık kanülize edildi. Devamında floroskopi eşliğinde kılavuz tel darlığın distaline ilerletildi. Darlığın uzunluğu ve yeri, ERKP kateterinden suda eriyen kontrast madde verilerek ölçüldü. Stent uzunluğu, darlık uzunluğunu proksimalde ve distalde 2-3 cm geçecek şekilde belirlendi. Klavuz tel darlığın distalinde kalacak şekilde bırakılarak ERKP kateteri endoskopun çalışma kanalından çekilerek çıkarıldı. Belirlenmiş olan uygun uzunlukta duodenal kapsız KGMS (Boston Scientific Japan, Tokyo, Japonya) floroskopi altında kllavuz tel üzerinden darlık bölgesini geçecek şekilde yerleştirildi. Stent, floroskopi ve endoskopi eşliğinde açldıktan sonra stentin açılmış durumu ve lokalizasyonu yine aynı yöntemler ile değerlendirildi. Bütün prosedürler, tecrübeli dört endoskopist tarafından gerçekleştirildi.

Duodenal KGMS yerleştirilmeden önce ve yerleştirildikten iki hafta sonra hastaların GOOSS skorları hesaplanarak klinik başarı değerlendirildi. Teknik başarı ise stentin darlığa uygun pozisyonla yeterli şekilde yerleştirilmesi olarak tanımlandı. Işleme bağlı gelişen komplikasyonlar minör ve majör komplikasyonlar olarak ayrıldı. Karın ağrısı, bulantı ve kusma gibi hayatı tehdit etmeyen komplikasyonlar minör iken, majör komplikasyonlar ise aspirasyon pnömonisi, sepsis, kanama ve perforasyon gibi yaşamı tehdit eden komplikasyonlar olarak tanımlandı (23). Stent açıklı̆̆ı süresi, stent yerleşimi ile stent disfonksiyonu veya hastanın ölümüne kadar geçen zaman periyodu olarak tanımlandi.

Hastaların verileri hastanemizde kullanılan AviCenna Hastane Bilgi Yönetim Sisteminden (Datasel information systems, Ankara, Türkiye) alındı. AviCenna Hastane Bilgi Yönetim Sistemi tıp alanında uluslararası kabul görmüş standartları (ICD-10, SNOMED, ATC, GMDN, vb.) desteklemektedir. Istatistik analizleri SPSS 20.0 (SPSS Inc., Chicago, IL, USA) programı kullanılarak yapıldı. Değisskenlerin normal dağılıma uygunluğu görsel (histogram ve olasıllk grafikleri) ve analitik yöntemler (Kolmogorov-Smirnov/Shapiro-Wilk testleri) ile incelendi. Tanımlayıcı analizler normal dağılan değişkenler için ortalama \pm standart sapma verilerek yapıldı. Normal dağılmayan değişkenler için ortanca ve çeyrekler arası kullanılarak verildi. Klinik başarı ile cinsiyet arasında, gruplar arasında fark bulunup bulunmadığı ki-kare ya da Fisher testleri ile klinik başarı stent uzunluğu ve OSSS arasındaki fark Mann_Whitney U testi ile değerlendirildi. P değerinin 0.05'in altında olduğu durumlar da istatiksel olarak anlamlı sonuçlar şeklinde değerlendirildi.

\section{BULGULAR}

Çalışma süresince intraabdominal maligniteye bağlı gelişen inoperabl MMÇO bulunan toplam 28 hastaya palyatif amaçlı endoskopik yöntemle duodenal kapsız KGMS yerleştirildi. Bu hastaların 18'i (\% 64.3) erkek ve 10'u (\%35.7) kadındı. Hastaların yaş ortalaması 60.9 (42-92) yıl idi. Pankreas (10 hasta, \%35.7) ve mide (9 hasta, \%32.1) kanserleri, MMÇO'na en sık neden olan tümörlerdi. Diğer nedenler ise sırasıyla kolanjiyokarsinom (3 hasta, \%10.7), periampüller karsinom (3 hasta, \%10.7), duodenum kanseri (1 hasta, \%3.6), kolon kanseri (1 hasta, \%3.6) ve safra kesesi kanseri (1 hasta, \%3.6) idi. 
Hastaların tamamında histopatolojik olarak malignite tanısı vardı. Cerrahi olarak gastrointestinal anatomisi değiştirilen 3 (\% 10.7) hastanın cerrahi anastomozunda malign darlik izlendi. MMÇO, 20 (\%71.4) hastada duodenumda iken, 8 (\%28.6) hastada mide distalinde saptandi. Duodenumda saptanan malign darlık lokalizasyonlarının dağılımı ise 1. kısımda 8 (\%40), 2. kisimda 8 (\%40), 3. ve 4. kisimda 4 (\%20) hasta şeklinde idi.

Teknik başarı 28 hastanın tamamında (\%100) sağlandı. Klinik başarı ise 25 ( 89.3) hastada sağlandı. Klinik başarı sağlanmayan üç (\%10.7) hastanın GOOSS skorunda herhangi bir artış ve azalma tespit edilmedi. Bu hastalar için GOOSS skorları 2 hastada 1 ve 1 hastada 2 idi. Hastaların işlemden önce ve işlemden iki hafta sonra ölçülen GOOSS skorları Tablo l'de özetlendi. Buna göre işlemden önce GOOSS skoru, 13 (\% 46.4) hastada 0, 12 (\% 42.9) hastada 1 ve 3 (\% 10.7) hastada 2 olarak belirlendi. İşlemden iki hafta sonra ise 3 (\% 10.7) hastada 1,11 (\%39.3) hastada 2 ve 14 (\%50) hastada 3 olarak ölçüldü. Tüm hastaların GOOSS skoru ortalaması duodenal stent yerleştirmeden önce 0.536 iken yerleştirildikten iki hafta sonra anlamlı olarak daha yüksek olup, 2.39' du ( $\mathrm{P}=0.0001)$.

Çalışmaya alınan tüm hastalar (n=28) takiplerinde altta yatan hastalığa bağlı olarak öldüler. Hastaların ortanca sağ kalım süresi 98 (25-524) gün idi. Stent açıklığının ortanca süresi 94 (22-491) gün saptandı. İlem süresi boyunca 4 hastada (\%14.3) stent disfonksiyonu gelişti. Bu 4 hastada tümörün progresyonu vardı. İkisine önceki stent için yeni duodenal KGMS yerleştirilirken diğer ikisine balon dilatasyonu uygulandı. Stent disfonksiyonu tekrAar gelişmeden dört hastada öldü.

Majör 2 (7.14) ve minör 2 (\%7.14) olmak üzere toplam 4 (\%14.3) hastada işleme bağlı komplikasyon gelişti. İi (\% 7.14) hastada karın ağrısı, bir hastada (\%3.57) aspirasyon pnömonisi ve bir hastada (\%3.57) sepsis gelişmiş olup hastaların hepsi medikal tedavi ile düzeldi. Işleme bağlı duodenal perforasyon ve ölüm izlenmedi.

\section{TARTIŞMA}

Çalışmamızda küratif cerrahiye uygun olmayan MMÇO olan hastalarda palyatif tedavi amaçlı endoskopik yöntemle uygulanan duodenal kapsız KGMS sonuçları retrospektif olarak değerlendirildi. Teknik başarı \%100 ve klinik başarı \%89.3 oranında sağlandı. Stent açıklık süresinin hasta sağ kalım süresi için kabul edilebilir olduğu gösterildi.

MMÇO’lu hastaların büyük çoğunluğu inoperabl olup obstrüktif semptomları hafifletmek için palyatif tedavi yöntemlerine ihtiyaç duymaktadırlar. Bu amaçla eskiden genellikle cerrahi yöntem olan GJ yapılmaktaydı. Günümüze ise daha çok duodenal KGMS kullanılmaktadır. Bu iki yöntem karşılaştırıldığında GJ, önemli mortalite ve morbidite oranı, hastanede kalış süresinin uzaması, semptomların hafiflemesinde gecikme ve yüksek maliyet ile ilişkilidir (24-26). No ve arkadaşlarının yaptıkları çalışmada KGMS uygulanan hastalara göre GJ yapılan hastalarda daha iyi sağ kalım sağlandığı bildirilmiştir (27). Bunun tersine, Espinel ve arkadaşlarının yaptıkları çalışmada ise 30 günlük mortalite oranı GJ yapılanlara $(\% 29,4)$ göre enteral stent takılanlarda $(\% 16,6)$ daha düşük olduğu raporlanmakla beraber (24) komplikasyon oranlarının GJ grubuna $(\% 17,6)$ göre enteral stent grubunda (\%4) daha düşük olduğu bildirildi. Ayrıca, MMÇO'lu hastaların çoğu kanserin son aşamasında olup cerrahi yöntemleri tolere edememekte ve sinırlı ömür beklentilerine sahiptirler. $\mathrm{Bu}$ nedenlerden dolayı günümüzde, KGMS kullanımına eğilim giderek artmaktadır.

Teknik başarı 28 hastanın tamamında (\% 100) sağlandı. Teknik başarı oranları önceki çalışmaların bazılarında \%94-98 olarak bildirilmiş olmakla beraber çoğunda çalışmamıza benzer şekilde \%100 olarak rapor edilmiştir (8-20). Darlığın şiddeti nedeniyle kılavuz telin veya stent taşıma sisteminin başarısız geçişi, işlem sırasında perforasyon, stentin yetersiz yerleştirilmesi ve stentin migrasyonu teknik başarsızlığın nedenleri olarak önceki çalışmalarda bildirilmiştir $(9,11,12,15,18)$. Klinik başarı \%89.3 oranında saptandı. Hastaların GOOSS skoru ortalaması işlemden önce 0.536 iken işlemden iki hafta sonra 2.39'a yükseldiği belirlendi $(\mathrm{P}=0.0001)$. Klinik başarı

\section{Tablo 1. Duodenal KGMS yerleştirilmeden önce ve yerleştirildikten iki hafta sonra hastaların GOOSS skorları}

\begin{tabular}{|c|c|c|c|c|c|}
\hline & \multicolumn{2}{|c|}{ KGMS Yerleştirilmeden Önce } & \multicolumn{2}{|c|}{ KGMS Yerleştirildikten İki Hafta Sonra } & \multirow[b]{2}{*}{ P değer } \\
\hline GOOSS Skoru & Sayı & Yüzde & Sayl & Yüzde & \\
\hline 0 & 13 & 46.4 & 0 & 0 & \\
\hline 1 & 12 & 42.9 & 3 & 10.7 & 0.0001 \\
\hline 2 & 3 & 10.7 & 11 & 39.3 & \\
\hline 3 & 0 & 0 & 14 & 50 & \\
\hline Ortalama & \multicolumn{2}{|c|}{0.536} & \multicolumn{2}{|c|}{2.39} & 0.0001 \\
\hline
\end{tabular}

KGMS: Kendiliğinden genişleyebilen metal stent, GOOSS: Gastrik Outlet Obstrüksiyon Skorlama Sistemi. 
tanımları çalışmalar arasında farklılık göstermesine rağmen, \%77-94 arasında değişen klinik başarı oranları bildirilmiştir (8-20).

Hastalarda \%7.- minör ve \%7.- majör olmak üzere toplam \%14.- oranında komplikasyon gelişti. Gelişen komplikasyonların hepsi medikal tedavi ile düzeldi. Issleme bağlı ölüm görülmedi. Daha önce yapılan benzer çalışmalarda komplikasyon oranları \% 0-23 gibi geniş bir aralıkta bildirilmiştir (8-20). Hastaların ortanca sağ kalım süresi 98 (25-524) gün olarak belirlendi. Önceki çalışmalarda ise ortanca sağ kalım sürelerinin 49-186 gün arasında değiştiği rapor edilmiştir (820). Stent açıklığının ortanca süresi 94 (22-491) gün olarak bulundu. Bu sürenin diğer çalışmalarda 39 ile 307 gün arasında değiştiği rapor edilmiştir $(8,9,11,14,16-19)$. Çalışma süresince \%14.3 aranında stent disfonksiyonu gelişti. Daha önce yapılan benzer çalışmalarda ise \%5-40 gibi geniş bir aralıkta rapor edilmiștir (8-20). Çoğu raporda stent disfonksiyonu oranı çalışmamızda olduğu gibi \%30'dan az olsa da, Nassif ve arkadaşlarının yaptıkları çalışmada \%40 oranında bildirilmiştir (8).

Çalışmamızın bazı sınılandırmaları mevcuttu. Retrospektif bir çalışma olmasına rağmen, endoskopi ünitemizde hastaların verileri kayıt defterinde ve bilgisayar ortamında iyi saklanmaktadır. Ikinci olarak, çalışmaya katılan hasta sayısı istenen düzeyde değildi, ancak tek merkezli olduğu dikkate alınmalıdır.

Sonuç olarak, çalışmamızda saptanan bulgular ve literatürdeki bilgiler ışığında küratif cerrahi şansı olmayan MGOO'lu hastalarda endoskopik olarak uygulanan duodenal KGMS yöntemi güvenli ve etkili bir palyatif yöntemdir.

\section{KAYNAKLAR}

1. Lillemoe KD, Cameron JL, Hardacre JM, et al. Is prophylactic gastrojejunostomy indicated for unresectable periampullary cancer? A prospective randomized trial. Ann Surg 1999;230:322-8.

2. Lopera JE, Brazzini A, Gonzales A, et al. Gastroduodenal stent placement: current status. Radiographics 2004;24:1561-73.

3. Adler DG, Baron TH. Endoscopic palliation of malignant gastric outlet obstruction using self-expanding metal stents: experience in 36 patients. Am J Gastroenterol 2002;97:72-8.

4. van Heek NT, van Geenen RC, Busch OR, et al. Palliative treatment in "peri"-pancreatic carcinoma: stenting or surgical therapy? Acta Gastroenterol Belgica. 2002;65:171-5.

5. Monson JR, Donohue JH, McIlrath DC, et al. Total gastrectomy for advanced cancer. A worth while palliative procedure. Cancer 1991;68:1863-8.

6. Ly J, O'Grady G, Mittal A, et al. A systematic review of methods topalliate malignant gastric outlet obstruction. Surg Endosc 2010;24:290-7.

7. Bozzetti F, Bonfanti G, Audisio RA, et al. Prognosis of patients after palliative surgical procedures for carcinoma of the stomach. Surg Gynecol Obstet 1987;164:151-4.

8. Nassif T, Prat F, Meduri B, et al. Endoscopic palliation of malignan gastric outlet obstruction using self-expandable metallic stents: results of a multicenter study. Endoscopy 2003;35:483-9.

9. Telford JJ, Carr-Locke DL, Baron TH, et al. Palliation of patients with malignant gastric outlet obstruction with the enteral Wallstent: outcomes from a multicenter study. Gastrointest Endosc 2004;60:916-20.

10. Graber I, Dumas R, Filoche B, et al. The efficacy and safety of duodenal stenting: a prospective multicenter study. Endoscopy 2007;39:784-7.

11. Kim JH, Song HY, Shin JH, et al. Metallic stent placement in the palliative treatment of malignant gastroduodenal obstructions: prospective evaluation of results and factors influencing outcome in 213 patients. Gastrointest Endosc 2007;66:256-64.

12. Maetani I, Isayama H, Mizumoto Y. Palliation in patients with malignant gastric outlet obstruction with a newly designed enteral stent: a multicenter study. Gastrointest Endosc 2007;66:355-60.

13. Piesman M, Kozarek RA, Brandabur JJ, et al. Improved oral intake after palliative duodenal stenting for malignant obstruction: a prospective multicenter clinical trial. Am J Gastroenterol 2009;104:2404-11.

14. van Hooft JE, Uitdehaag MJ, Bruno MJ, et al. Efficacy and safety of the new WallFlex enteral stent in palliative treatment of malignant gastric outlet obstruction (DUOFLEX study): a prospective multicenter study. Gastrointest Endosc 2009;69:1059-66.

15. van Hooft JE, van Montfoort ML, Jeurnink SM, et al. Safety and efficacy of a new non-foreshortening nitinol stent in malignant gastric outlet obstruction (DUONITI study): a prospective, multicenter study. Endoscopy $2011 ; 43: 671-5$.

16. Costamagna G, Tringali A, Spicak J, et al. Treatment of malignant gastroduodenal obstruction with a nitinol self-expanding metal stent: an international prospective multicentre registry. Dig Liver Dis 2012;44:37-43.

17. Sasaki T, Isayama H, Maetani I, et al. Japanese multicenter estimation of WallFlex duodenal stent for unresectable malignant gastric outlet obstruction. Dig Endosc 2013;25:1-6.

18. Miyabe K, Hayashi K, Nakazawa T, et al. Safety and benefits of self-expandable metallic stents with chemotherapy for malignant gastric outlet obstruction. Dig Endosc 2015;27:572-81.

19. Kato H, Kawamoto H, Matsumoto K, et al. Outcome of self-expandable metallic stent deployment in patients with malignant gastroduodenal outlet obstruction and Niti-S and WallFlex comparison: a multicenter retrospective clinical study. J Dig Dis 2016;17:518-25.

20. Sasaki R, Sakai Y, Tsuyuguchi T, et al. Endoscopic management of unresectable malignant gastroduodenal obstruction with a nitinol uncovered metal stent: A prospective Japanese multicenter study. World J Gastroenterol 2016;22:3837-44.

21. Jeurnink SM, van Eijck CH, Steyerberg EW, et al. Stent versus gastrojejunostomy for the palliation ofgastric outlet obstruction: a systematic review. BMC Gastroenterol 2007;7:18.

22. Hosono S, Ohtani H, Arimoto Y, et al. Endoscopic stenting versus surgical gastroenterostomy for palliation of malignant gastroduodenal obstruction: a meta-analysis. J Gastroenterol 2007;42:283-90.

23. Kim JH, Song H-Y, Shin JH. Malignant gastric outlet obstructions: treatment with self-expandable metallic stents. Gut Liver 2010;4 Suppl 1):\$32.

24. Espinel J, Sanz O, Vivas S, et al. Malignant gastrointestinal obstruction: endoscopic stenting versus surgical palliation. Surg Endosc 2006;20:1083-7.

25. Jeurnink SM, Steyerberg EW, Hof G, et al. Gastrojejunostomy versus stent placement in patients with malignant gastric outlet obstruction: a comparison in 95 patients. J Surg Oncol 2007;96:389-96.

26. Roy A, Kim M, Christein J, et al. Stenting versus gastrojejunostomy for management of malignant gastric outlet obstruction: comparison of clinical outcomes and costs. Surg Endosc 2012;26:3114-9.

27. No JH, Kim SW, Lim CH, et al. Long-term outcome of palliative therapy for gastric outlet obstruction caused by unresectable gastric cancer in patients with good performance status: endoscopic stenting versus surgery. Gastrointest Endosc 2013;78:55-62. 